\title{
Mechanical and Shielding Properties of Concrete Subject to Gamma-ray
}

\author{
S. Hosein Ghasemzadeh Mosavinejad*, Samira Kazemi Rad \\ Department of Civil Engineering, Engineering Faculty, University of Guilan, Rasht, Islamic Republic of Iran \\ Email: h.mosavi@guilan.ac.ir (Corresponding author)
}

Received: 11 July 2019; Accepted: 2 October 2019; Available online: 30 December 2019

\begin{abstract}
In this research, concrete with different percentages of 0, 10, 25, 50, 75 and 100 of barite powder and $10 \%$ of graphite powder were investigated for the study of gamma protective properties. The transmitted fluxes of gamma-rays that were emitted from Cs-137 source were detected by a $\mathrm{NaI}(\mathrm{Tl})$ detector and analyzed by an MCA analyzer. Then, the samples were tested for compressive strength, tensile strength, ultrasonic pulse wave velocity and the linear attenuation coefficients. By comparing the obtained samples, it was observed that a sample containing $10 \%$ barite powder plus $10 \%$ graphite powder could be used as a protective material against gamma rays.
\end{abstract}

Keywords: Gamma; Linear attenuation coefficient; Concrete.

\section{Introduction}

Artificially produced radiation and radioactive substances have been the result of the increased use of nuclear energy in industries and medical centers throughout the world. Hence, these have led to more attention and higher investment of countries in the area of design and construction of shielding structures.

Korkat et al. (2010) were performed nitrogen transfer measurements using a single energy $($ Eeff $=4.5 \mathrm{MeV})$ through single neutron source on four barite samples and four concrete samples with concentrations of $0,5,10$ and $15 \%$ of colemanite. This study showed that when the percentages of colemanite increase, the amount of neutron transport for the samples are reduced. It was concluded that by adding higher values of colemanite, the protective properties of neutrons of barite and conventional concrete can be increased [1]. El-Khayatt et al. (2010) studied the protection of $\gamma$ and fast neutrons in concrete specimens containing various lime/silica ratios. The total mass contraction coefficient $(\mu / \rho)$ was calculated and found that the ratio of lime and silica to concrete has significant effects on the value of $\mu / \rho$ [2]. Kharita et al. (2009) examined the effect of adding carbon powder on the properties of hematite concrete for radiation protection. They found out that the addition of $6 \mathrm{wt}$ \% Carbon to concrete has increased its resistance by about 15 percent. However, the protective properties for both gamma and neutron beam have decreased by increasing the amount of carbon powder [3]. Korkut et al. (2012) who studied the protective properties of neutrons in colemanite, Olixite and Tincal mines with varying degrees of boron observed that increasing the concentration of boron atoms could increase the protective properties of neutrons [4]. Azim Khani et al. (2012) investigated the protective properties of gamma-ray for various lead percentages in concrete. The results indicated that the addition of lead powders to $90 \%$ by weight of cement could be somewhat optimal [5]. Kensu (2013) found that magnetite concrete has better absorption properties than basalt concrete not only for slow and fast neutrons but also for gamma rays [6]. Madbouly et al. (2018) used standard concrete and five materials such as boron carbide, ilmenite, Ferro boron, Galina and barite, and concluded that concrete containing boron carbide is one of the best for protection against neutron radiation and barite is the best neutron reducer. Galina concrete can also be effective in protecting against gamma radiation [7].

In this research, the goal was to determine optimum percentage of barite powder as a substitute for sand singly and in combination with $10 \%$ graphite_not only as improving the mechanical properties of concrete but also as a protector of gamma nuclear radiation.

\section{Material and methods}

\subsection{Materials}

For this study, twelve mix designs, including control concrete specimen without silica fume, were prepared in two series. For both, type II cement with $400 \mathrm{~kg} / \mathrm{m} 3$, water to binder ratio of 0.4 , the maximum aggregate size of $19 \mathrm{~mm}$ accompanied by river sand graded to ASTM C33 standard [8] were utilized for concrete specimens. Gravel 
and sand gradation curves are shown in Figs 1 and 2, respectively. As it is shown in Table 1, sand is replaced by varying percentages of barite powder.

Density and water absorption of Barite powder are respectively $4.2 \mathrm{gr} / \mathrm{cm} 3$ and $0.24 \%$ and that for graphite powder are respectively, $2.22 \mathrm{gr} / \mathrm{cm} 3$ and $0.24 \%, 0.01 \%$. The all specimens, excluding the first two in table 1 , are made with varying percentages of 10, 25, 50, 75 and 100 percent

of barite powder as sand replacement containing 10\% silica fume singly (first series) and combined with $10 \%$ graphite powder (second series). Standard prefabricated cubic samples $(10 \mathrm{~cm})$ were subjected to compressive strength, ultrasonic pulse wave velocity and gamma-ray (the CS-137 fountain) tests.

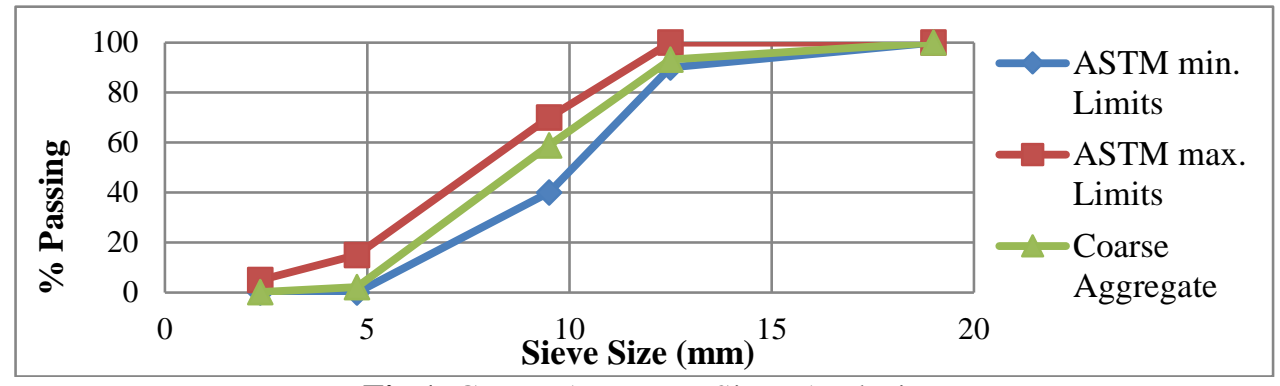

Fig.1. Coarse Aggregate Sieve Analysis.

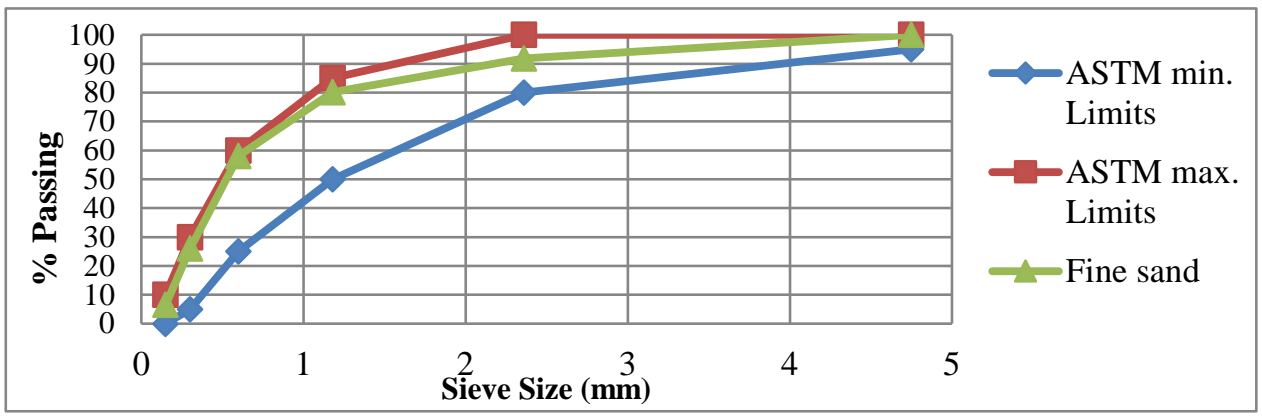

Fig.2. Fine sand Sieve Analysis.

Table 1. Concrete mix design per cubic meter $\left(\mathrm{Kg} / \mathrm{m}^{3}\right)$

\begin{tabular}{llllllll}
\hline Mixed type & Cement & Gravel & sand & W/C & Barite \% & Graphite \% & Silica fume \\
\hline CC & 400 & 860 & 820 & 0.4 & - & - & - \\
MS10 & 360 & 860 & 820 & 0.4 & - & - & 40 \\
Ba10 & 360 & 860 & 738 & 0.4 & 10 & - & 40 \\
Ba25 & 360 & 860 & 615 & 0.4 & 25 & - & 40 \\
Ba50 & 360 & 860 & 410 & 0.4 & 50 & - & 40 \\
Ba75 & 360 & 860 & 205 & 0.4 & 75 & - & 40 \\
Ba100 & 360 & 860 & 0 & 0.4 & 100 & - & 40 \\
Ba10G10 & 320 & 860 & 738 & 0.4 & 10 & 10 & 40 \\
Ba25G10 & 320 & 860 & 615 & 0.4 & 25 & 10 & 40 \\
Ba50G10 & 320 & 860 & 410 & 0.4 & 50 & 10 & 40 \\
Ba75G10 & 320 & 860 & 205 & 0.4 & 75 & 10 & 40 \\
Ba100G10 & 320 & 860 & 0 & 0.4 & 100 & 10 & 40 \\
\hline
\end{tabular}

\subsection{Test specimens and method}

Cubic test specimens of $10 \mathrm{~cm}$ were used to determine the compressive strength of 28 days wet cured specimens. Test specimens were tested according to BS 1881: part 116 at a loading rate of $2.5 \mathrm{KN} / \mathrm{s}$.

The ultrasonic pulse rate was also measured on $10 \mathrm{~cm}$ cube specimens after 28-days curing. This test is performed according to the ASTM C597 standard. In the arrangement of transducers, the direct method, was used with the $60 \mathrm{kHz}$ pulse frequency. The pulse transfer time is measured to an accuracy of 0.1 microseconds. According to the recommendations of other researchers, the optimal frequency for the evaluation of concrete is in 
the range of 48-80 kHz [9]. Furthermore, cubic specimens of $10 \mathrm{~cm}$ were subjected also to gamma rays emitted from the Cs-137 spring at 3.5 MPa for 10 minutes. The irradiation image is shown in Fig3. The detector used was sodium third mate $\mathrm{NaI}(\mathrm{Tl}), 2^{\prime \prime} \times 2^{\prime \prime}$, and multichannel MCA analyzer and Cassy Lab software for analysis of the results. The voltage applied to the detector was $500 \mathrm{~V}$. To reduce the background radiation, a lead guard detector is placed. Concrete samples are placed at a distance of $2 \mathrm{~cm}$ from the detector and $1 \mathrm{~cm}$ from the fountain.

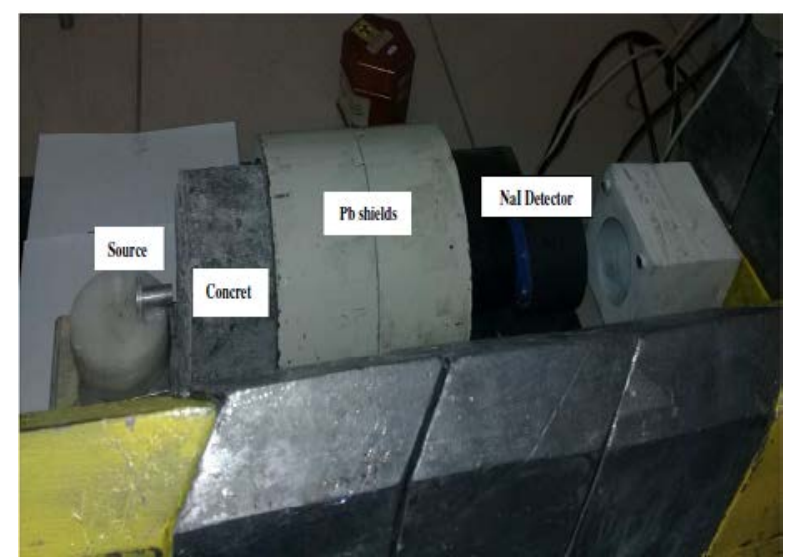

Fig. 3. Image of the radiation test by gamma source and counting by the $\mathrm{NaI}(\mathrm{Tl})$ detector.

\section{Results and discussion}

\subsection{Density}

Fig 4 shows the result of 28-day samples density. The presence of barite powder and graphite powder increases the density of concrete, in particular for samples Ba75G10 and Ba100G10, which places them in the heavy concrete category.

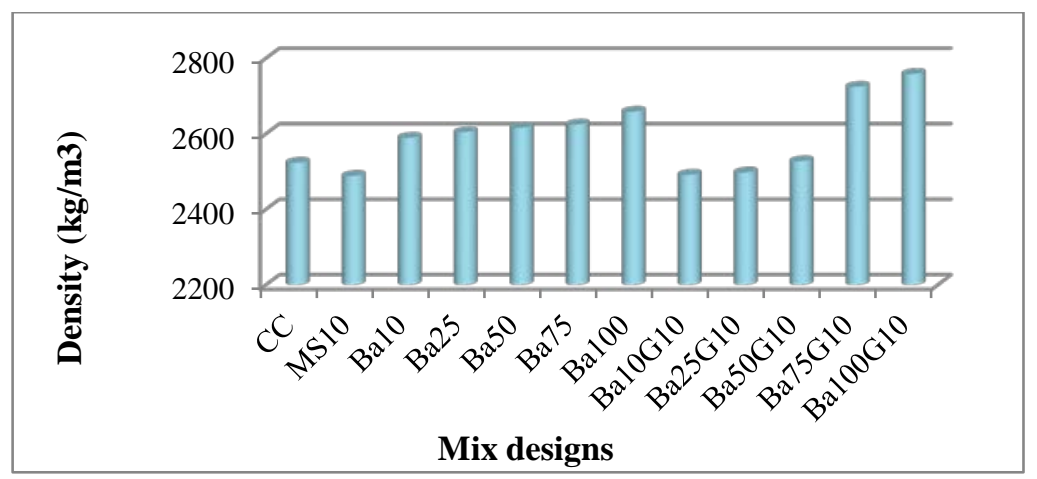

Fig. 4. 28-day density change

\subsection{Compressive strength}

The compressive strength results of specimens at the age of 28 days is shown in Fig5. The results indicate that by increasing the percentage of barite powder, the compressive strength decreases. Also, the presence of $10 \%$ graphite powder in the second series will further intensify the compressive strength reduction. The reason for this phenomenon can be attributed to the low water absorption of barite powder, which reduces their adhesion to the cement paste. Also, this reduction will further increase when graphite powder is introduced. Due to the low water absorption, their adhesion to cementitious materials is reduced to some extent, which leads to the reduction of compressive strength. Moreover, the increase in density with the presence of barite and graphite powders, does not enhance the compressive strength of the specimens. The incremental and decreasing trend of strength in the first and second series of samples is almost the same and indicates that compressive strength of the control concrete is higher as compared to the concrete containing barite powder.

\subsection{Tensile strength}

The illustrated halved cross sectioned of the Brazilian test cylinder is shown in Fig 6 . Fig 7 shows the tensile strength for 28-day samples which is directly proportional to the compressive strength. As it is observed, its increasing or decreasing trend is almost as strong as compressive strength. Also shown in Figure 8 is the 
relationship between compressive and tensile strength. It can be concluded from Fig 7 that the tensile strength depends only on the nature and size of the materials used in the concrete so that the tensile strength can be further increased to the existing cement paste and the adhesiveness of the compounds. Since the percentage of water absorption of barite is very low, hence the adhesion of the paste to the barite powder also decreases. Also, this decrease is much higher with graphite powder, but the incremental or decreasing trend of both series of samples is almost the same.

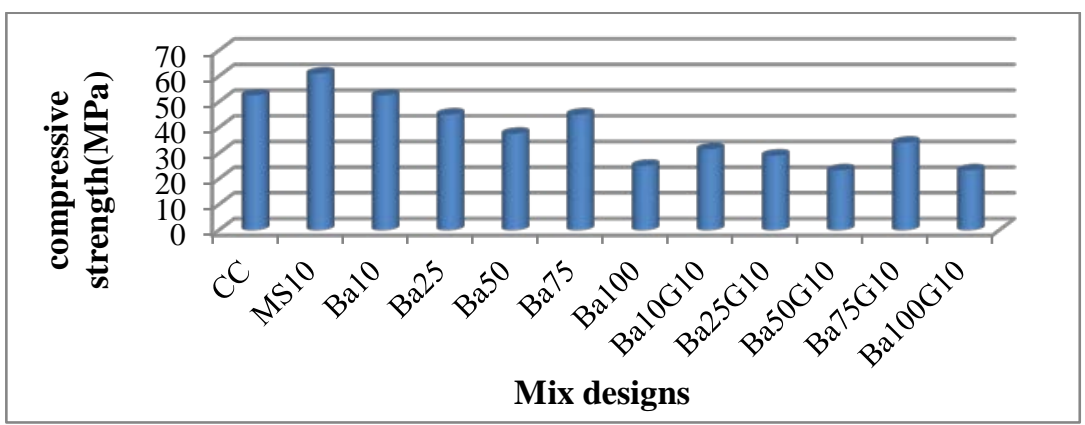

Fig. 5. 28-day compressive strength variations

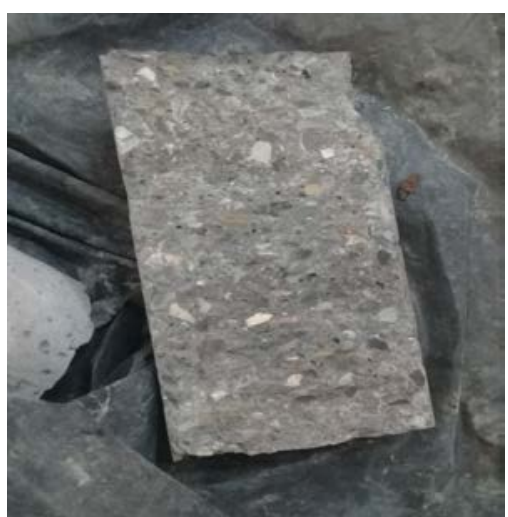

Fig. 6. Splitted sample image of Brazilian test

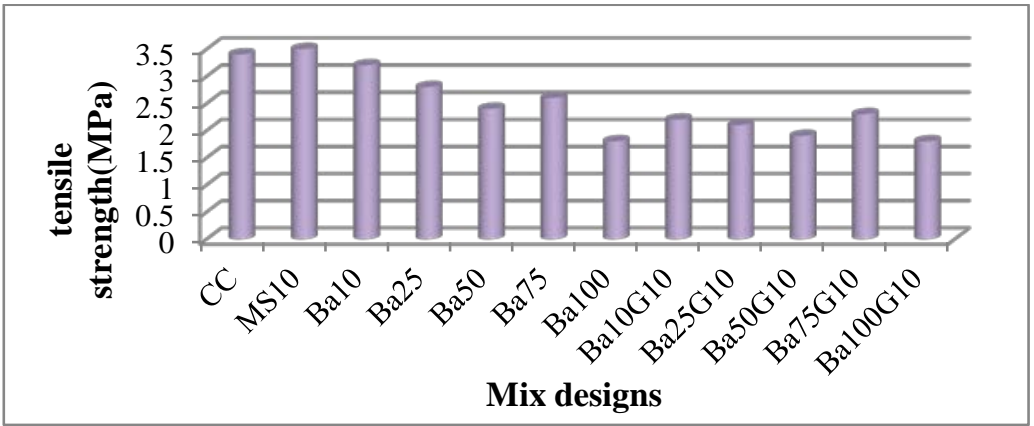

Fig.7 28-day tensile strength variations

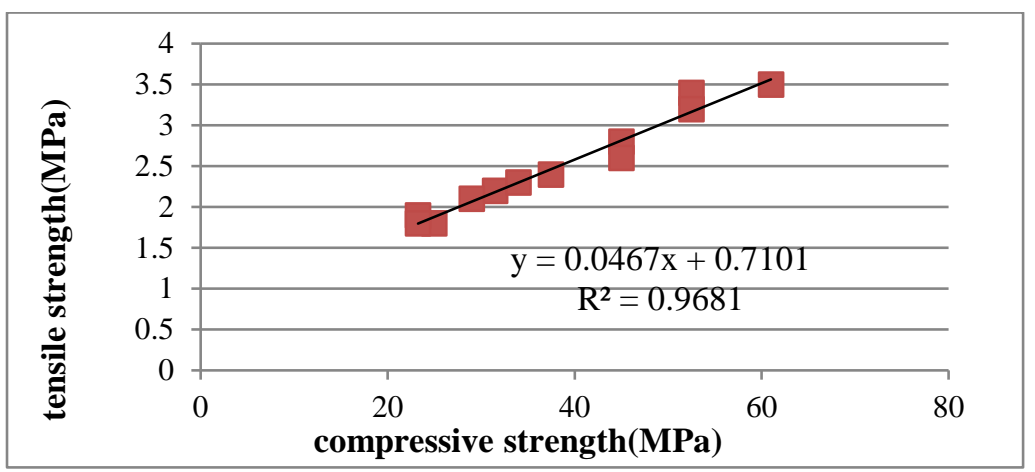

Fig. 8. The relationship between compressive and tensile strength 


\subsection{Ultrasonic pulse rate}

Good quality Concrete is classified according to ultrasonic pulse rate, $4500 \mathrm{~m} / \mathrm{s}$ and higher. As shown in Fig 9 , the pulse velocity values of all concrete mixtures are in the range of $4673 \mathrm{~m} / \mathrm{s}$ to $5263 \mathrm{~m} / \mathrm{s}$. Therefore, all concrete mixtures are considered as high-quality concrete. The lowest and highest pulse rate is for $100 \%$ barite with $10 \%$ graphite and the sample with $10 \%$ silica fume, respectively. According to the figure, the ultrasonic pulse rate of the sample containing $10 \%$ silica fume is higher than the rest of the mix designs, which suggests that this design has a better paste quality due to the pozzolanic and filling properties of silica fume than other samples. Also, the process of pulse velocity changes is in line with compressive strength variations, which indicates the accuracy of the tests.

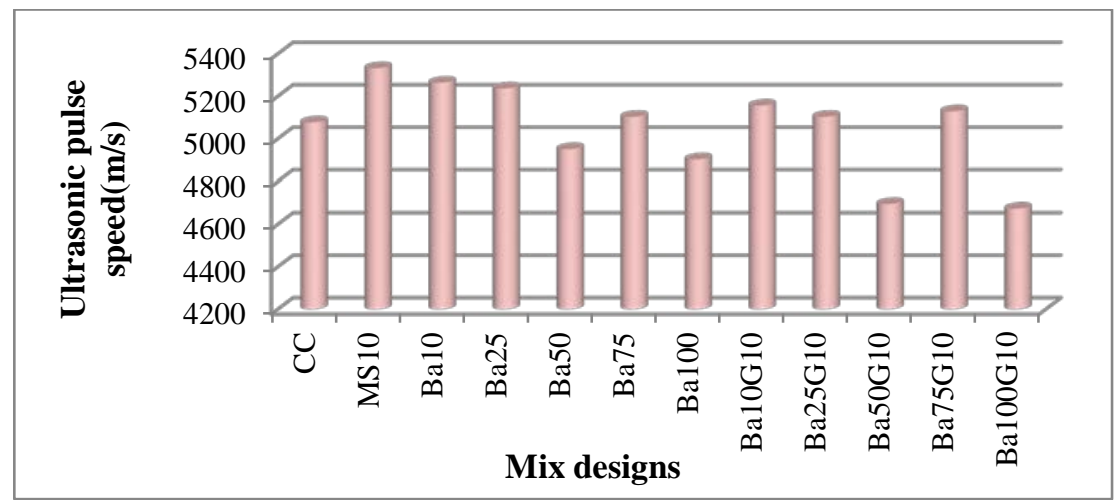

Fig. 9. Results of the ultrasonic pulse rate of all mixtures

\subsection{Water absorption}

Water absorption percentage is shown in Fig 10. It is observed that samples containing graphite powder will have a much lower water absorption rate. Also, the relationship between water absorption and compressive strength is shown in Fig 11 where there is a weak linear correlation coefficient.

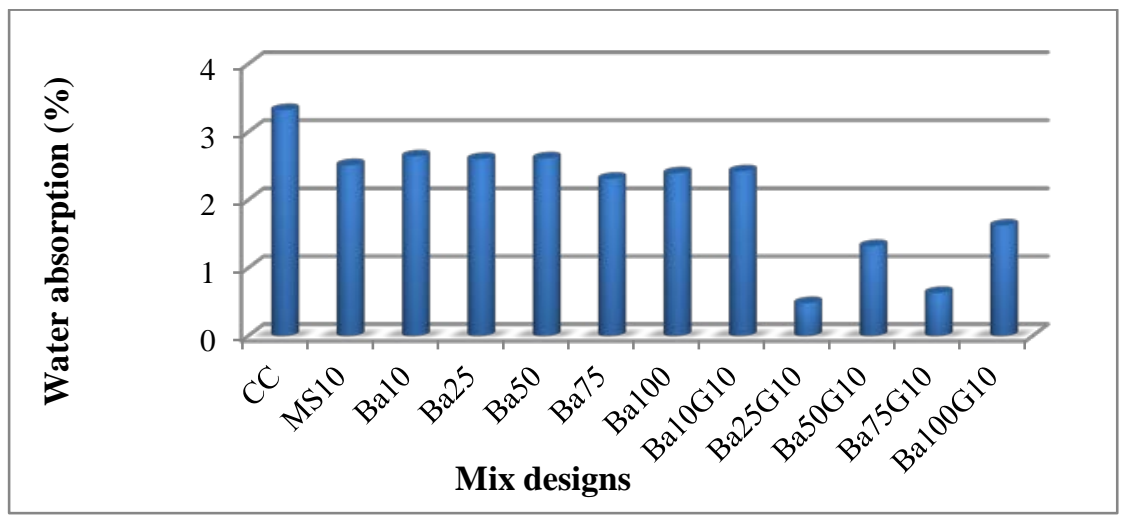

Fig. 10. 28-day water absorption of concrete mixtures

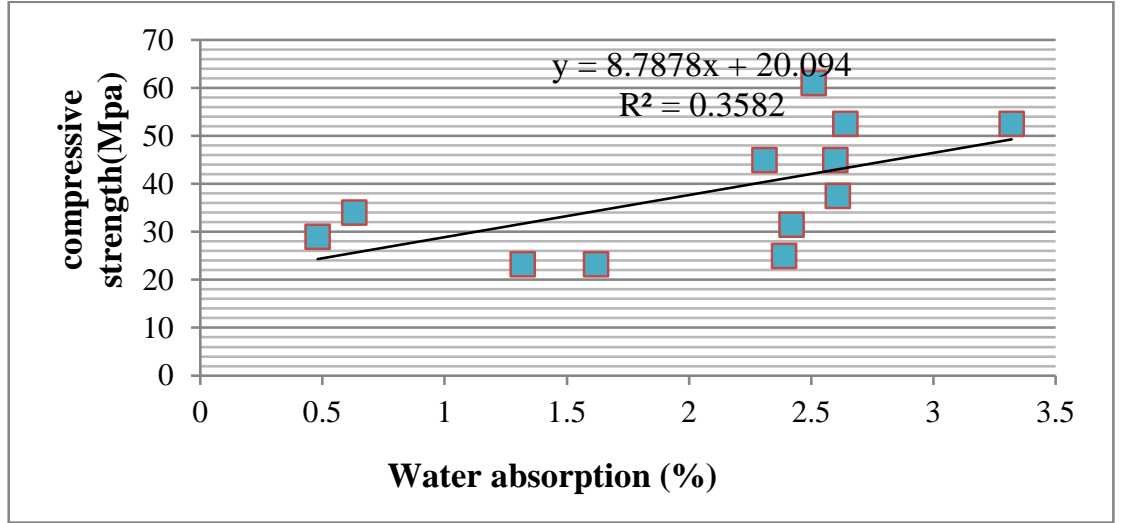

Fig. 11. Relationship between water absorption and compressive strength 


\subsection{Linear attenuation coefficients}

The linear attenuation coefficients of concrete mixtures are obtained by $\mathrm{N}=\mathrm{N}_{0} B e^{-\mu x}$, in which $\mathrm{x}$ is the thickness of the concrete in $\mathrm{cm}, \mathrm{N}_{0}$ and $\mathrm{N}$ represent counts in the absence and the presence of concrete protection, respectively. The values for $\mathrm{N}_{0}$ and $\mathrm{N}$ are obtained from the sum of the experimental curves of the beams. Usually, $\mathrm{B}=1$ is used for good geometry.

Fig 12 compares the linear gamma-ray attenuation coefficient in two series of mixtures, separately. This graph shows that the use of graphite powder increases the linear attenuation coefficient of the samples and can improve the coefficient of linear attenuation.

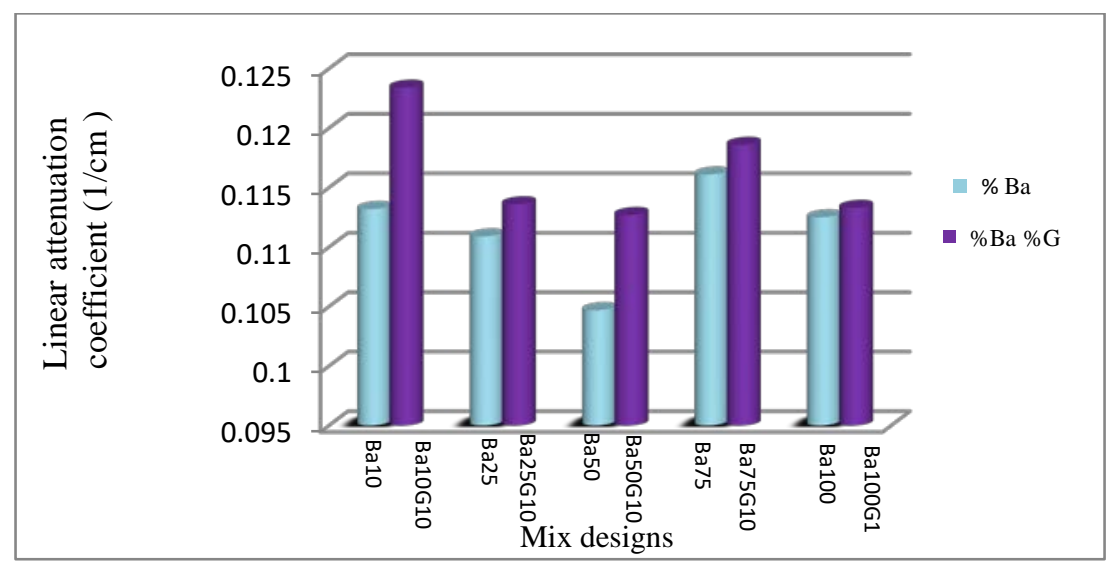

Fig. 12. Comparison of the linear attenuation coefficient of samples containing various percentages of barite powder and samples containing barite and graphite powders. Ba and G denotes barite graphite, respectively.

\subsection{Spectrophotometric analysis of EDS energy}

Figs 13 and 14, respectively, represent the magnified electron images of the square section marked on the shapes where the samples analysis chart is obtained from. Figures 15 and 16 illustrate the EDS test analysis chart for the control sample and the sample containing $10 \%$ barite plus $10 \%$ graphite. The cavities and dark portions shown in the images indicate porosities resulting from water evaporation and lack of good compaction due to low watercement ratio and these are far higher for the samples containing low water absorption and less cohesive barite and graphite powders.

The diagram of Fig 17 is obtained from the analysis chart and the weighted mass of selected samples as the minimum and maximum linear-gradient coefficients. From this comparison chart, it can be concluded that increasing the percentage of the elements, particularly oxygen and calcium, in the control sample and the one with $10 \%$ barite combined with $10 \%$ graphite powders can increase the linear depression coefficient of the samples.

EDS analysis was used to study the $\mathrm{Ca} / \mathrm{Si}$ ratio of the selected cement matrix. In the study of Pellenq et al. (2009) [10], the $\mathrm{Ca} / \mathrm{Si}$ ratio in C-S-H is reported to be a major contributor to the mechanical strength of the cementitious compound. In a molecular simulation, it is predicted that $\mathrm{Ca} / \mathrm{Si}$ of about 1 can create a cement mixture of 60 to $90 \%$ harder than a $\mathrm{Ca} / \mathrm{Si}$ concrete equivalent to 1.7 . EDS analysis of this study shows that the mean $\mathrm{Ca} / \mathrm{Si}$ in the control samples is higher than 1 and the mean of Ba10G10 samples is less than 1 and therefore has a higher compressive strength.
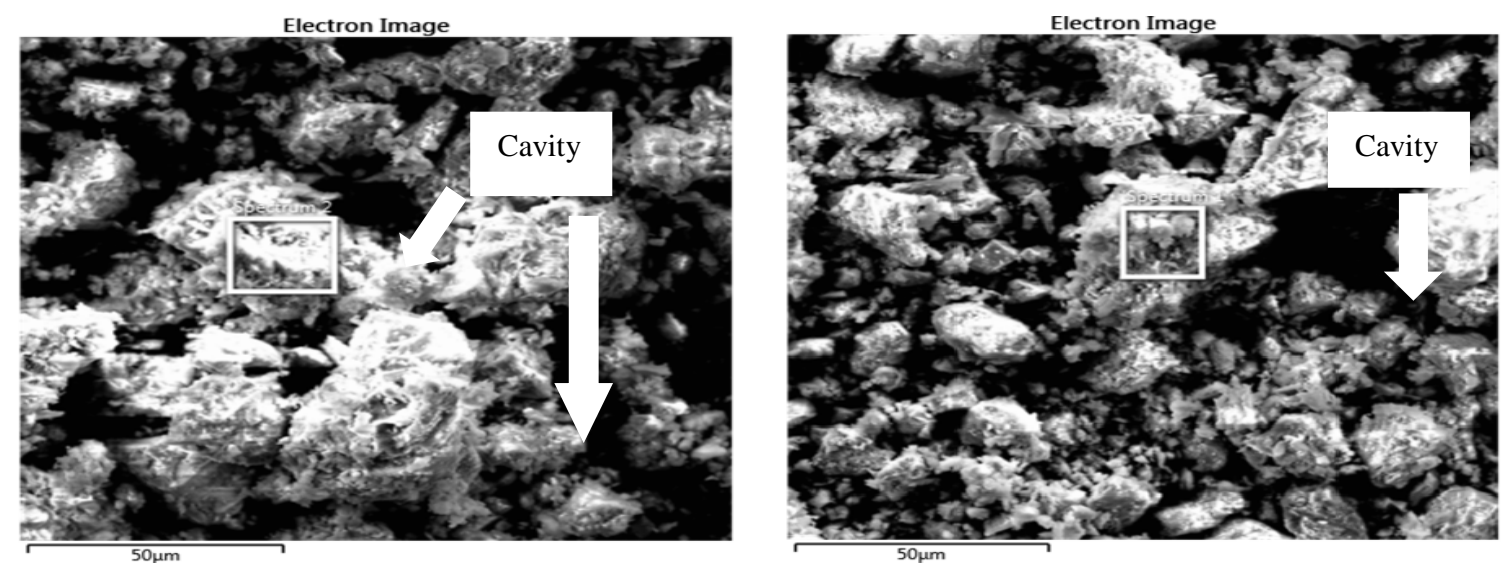

Fig. 13. Photographs taken by the EDS test for the control sample 

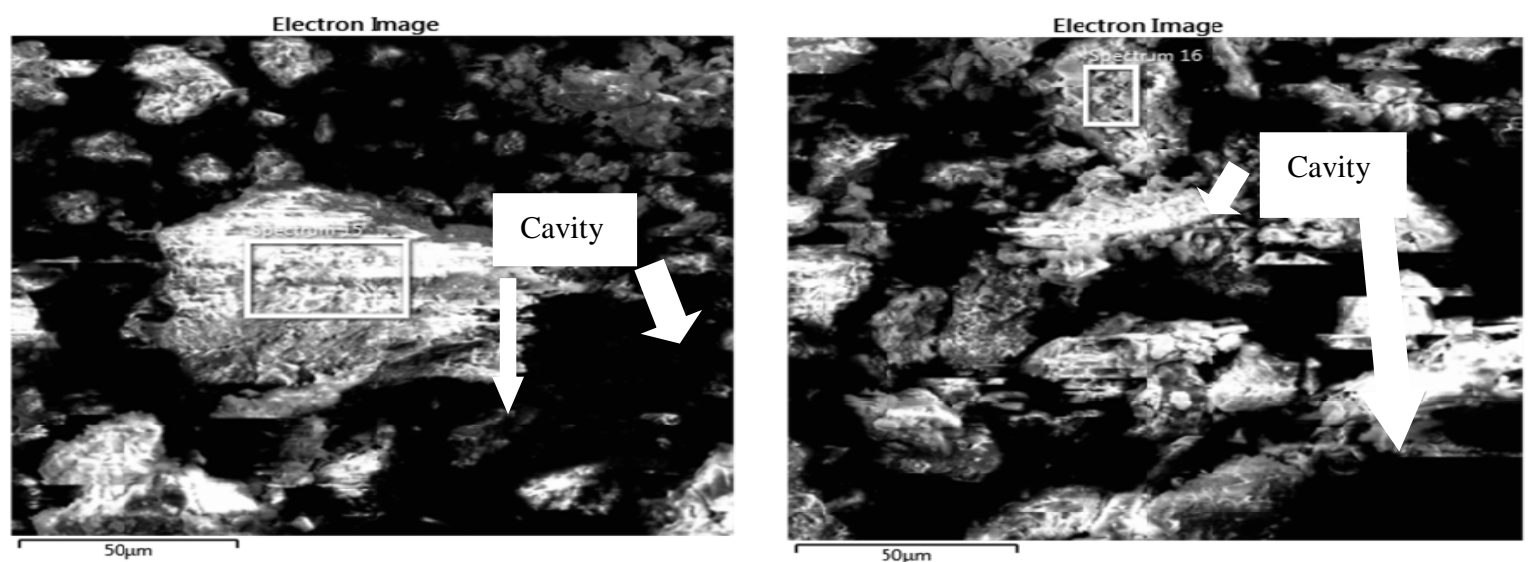

Fig. 14. Photographs taken by the EDS for the Ba10G10 sample
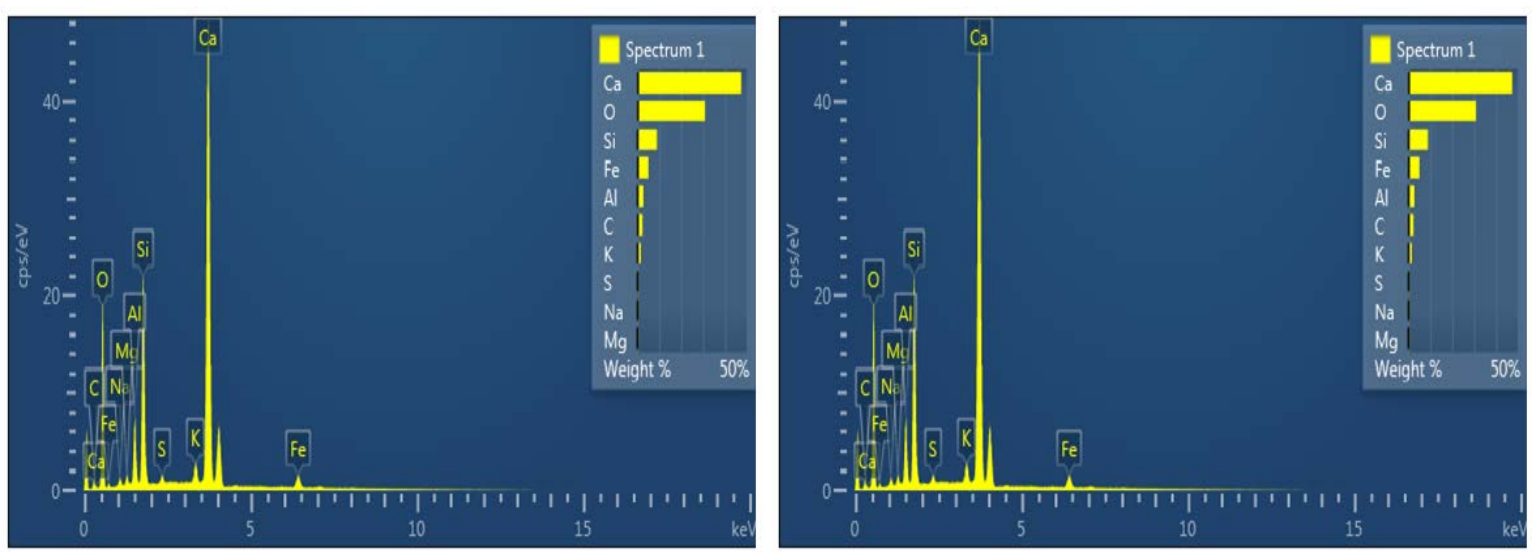

Fig. 15. Analysis chart of control sample under the EDS test
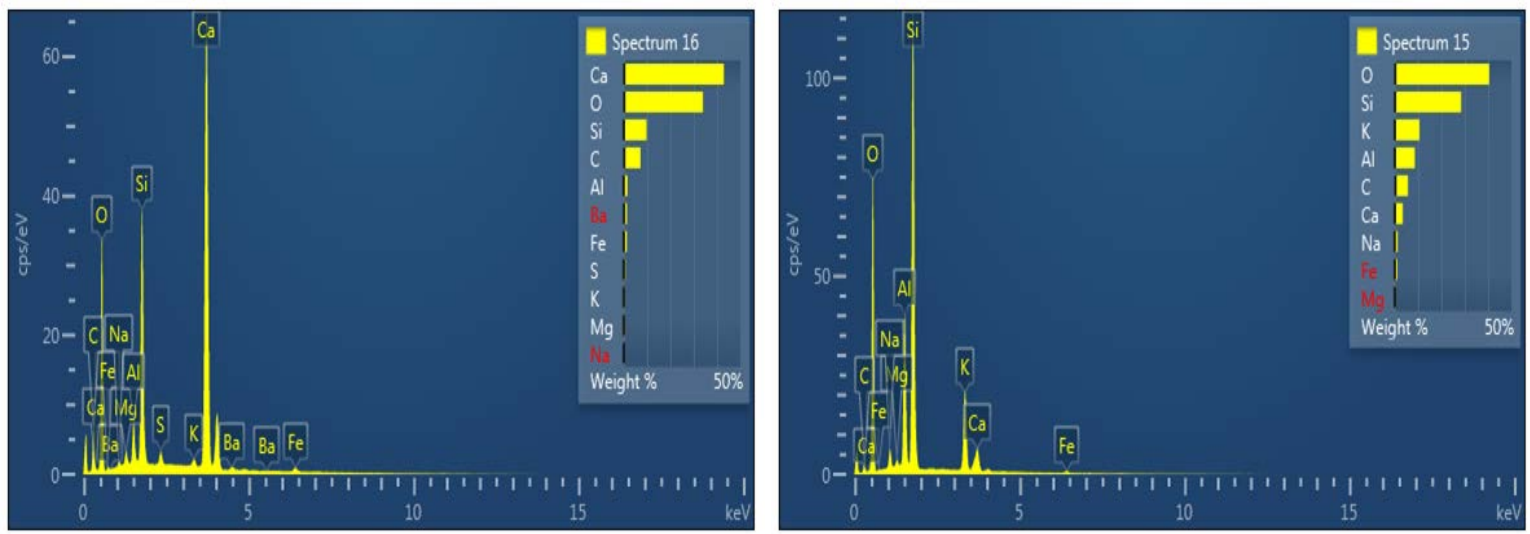

Fig. 16. Analysis chart of Ba10G10 under the EDS test

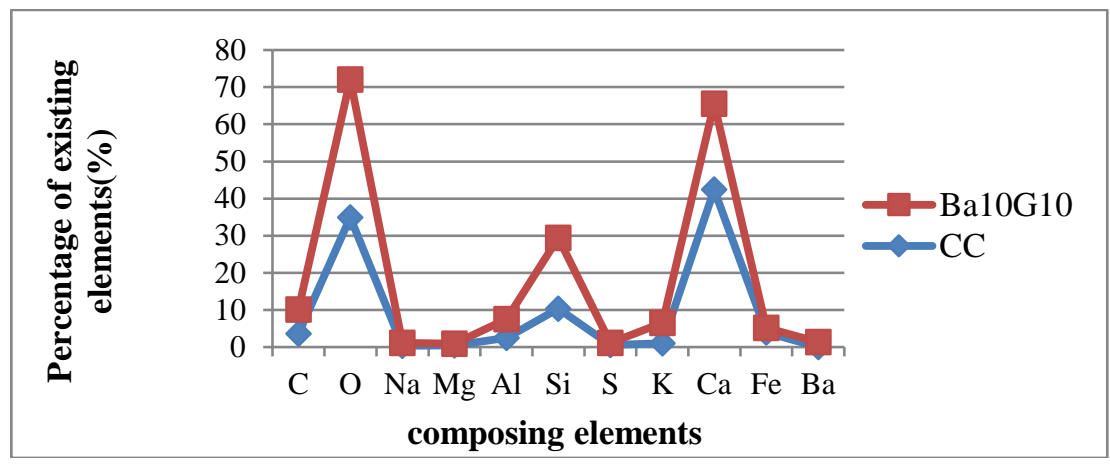

Fig. 17. Comparative graphs of the elements of the control sample and Ba10G10 


\section{Conclusions}

The most important conclusions are as follows:

1) The presence of barite powder and its combination with graphite lowers mechanical properties of concrete samples, but enhances gamma radiation protection.

2) Graphite powder has increased the linear attenuation of all samples but highest increase and shielding properties is observed for sample containing $10 \%$ barite with $10 \%$ graphite.

3) The presence of graphite powder in concrete increases the linear attenuation coefficient of the specimens.

\section{Acknowledgement}

The authors thanks to the laboratory staffs Mrs. Haj-Jafari, Mr. Sarmast and Mr. katebi of Guilan university and Dr. Azimkhani and Dr. Zolfaghari of Mohaghegh university for their cooperation in test setup equipment.

\section{References}

[1] Korkut T, Ün A, Demir F, Karabulut A, Budak G, Şahin R, Oltulu M. Neutron dose transmission measurements for several new concrete samples including colemanite. Annals of Nuclear Energy. 2010;37(7):996-998.

[2] El-Khayatt AM. Radiation shielding of concretes containing different lime/silica ratios. Annals of Nuclear Energy. 2010;37(7):991-995.

[3] Kharita MH, Yousef S, AlNassar M. The effect of carbon powder addition on the properties of hematite radiation shielding concrete. Progress in Nuclear Energy. 2009;51(2):388-392.

[4] Korkut T, Karabulut A, Budak G, Aygün B, Gencel O, Hançerlioğulları A. Investigation of neutron shielding properties depending on number of boron atoms for colemanite, ulexite and tincal ores by experiments and FLUKA Monte Carlo simulations. Applied Radiation and Isotopes. 2012;70(1):341-345.

[5] Rezaei-Ochbelagh D, Azimkhani S, Mosavinejad HG. Gamma-ray shielding properties of concrete with different percentages of lead. Nuclear Science and Techniques. 2012;23:215-218.

[6] Kansouh WA. Reactor fast and slow neutrons and total gamma rays distributions through different locally preparea concretes. Journal of Nuclear Energy Science \& Power Generation Technology. 2013;2(1).

[7] Madbouly AM, El-Sawy AA. Calculation of gamma and neutron parameters for some concrete materials as radiation shields for nuclear facilities. International Journal of Emerging Trends in Engineering and Development. 2018;3(8):7-17.

[8] ASTM, American Society for Testing and Materials. ASTM C33 standard specification for concrete aggregates. ASTM, Philadelphia, Pennsylvania; 2003.

[9] Abo-Qudais SA. Effect of concrete mixing parameters on propagation of ultrasonic waves. Construction and Building Materials. 2005;19(4):257-263.

[10] Pellenq RJ, Kushima A, Shahsavari R, Van Vliet KJ, Buehler MJ, Yip S, Ulm FJ. A realistic molecular model of cement hydrates. Proceedings of the National Academy of Sciences. 2009;106(38):16102-16107.

(C) 2019 by the author(s). This work is licensed under a Creative Commons Attribution 4.0 International License (http://creativecommons.org/licenses/by/4.0/). Authors retain copyright of their work, with first publication rights granted to Tech Reviews Ltd. 